\title{
DESDE FREIRE: CINQUENTA ANOS DA PEDAGOGIA DO OPRIMIDO E O FEMINISMO NO BRASIL
}

\author{
Rita de Cássia Machadoi \\ Conceição Paludo ii \\ Amanda Motta Castro ${ }^{\text {iii }}$
}

\begin{abstract}
Resumo: Esse artigo reúne uma síntese, de aspectos que as autoras já desenvolveram em outros textos, resultante de pesquisas, uma vez que temos, ao longo dos anos, Paulo Freire como um referencial. Assim como traz resultados de estudos sobre as mulheres e seus movimentos, teóricos e práticos, de libertação, que foram ocorrendo através do processo histórico, tendo como recorte o Brasil. A perspectiva teórica adotada é a do materialismo histórico dialético, e o objetivo consiste em estabelecer relações entre a pedagogia do oprimido, de Paulo Freire, e a luta de libertação das mulheres. Atuar de forma articulada e coerente, nesta frente, demonstra uma compreensão profunda de que um novo Projeto de Sociedade requer homens e mulheres libertos de qualquer tipo de exploração, dominação, discriminação e de violência. Participar desta luta é o que nos faz sermos mulheres em processo de libertação porque descentradas, abertas e construtoras das possibilidades de instituição de um projeto de futuro para o Brasil e para a humanidade.
\end{abstract}

Palavras chave: Opressão. Feminismo. Libertação.

\section{FROM FREIRE: FIFTY YEARS OF PEDAGOGY OF OPRIMIDO AND FEMINISM IN BRAZIL}

\begin{abstract}
In this article it'is gathered a synthesis of aspects that the authors have already developed in other texts, resulting from researchs developed by both of them over the years, having Paulo Freire thinking as a reference. It also brings studies results about woman and their emancipation theoretic and practical movements that occurred through the historical process, especially in Brazil. The theoretical perspective adopted is dialectical historical materialism and the objective is to establish relations between pedagogy of the oppressed, by Paulo Freire, and the woman emancipation struggle. On this front, acting in an articulate and coherent manner demonstrates a deep understanding that a new Society Project requires men and women free from any kind of exploitation, domination, discrimination and violence. Participating in this struggle is what makes us women in a emancipation process, because we are decentralized, opened and also possibilities builders to establish a project for Brazil and humanity future.
\end{abstract}

Keywords: Oppression. Feminism. Emancipation.

\section{Introdução}

\author{
Aos esfarrapados do mundo e aos que neles se descobrem e, assim descobrindo-se, com \\ eles sofrem, mas, sobretudo, com eles lutam. \\ (Freire, 1987, aplique esse pensamento as mulheres)
}


O sistema do capital continua cada vez mais perverso. O que hegemoniza é uma concepção que Claudio Katz ${ }^{\text {iv }}$ (2010) denomina como liberalismo ortodoxo - neoliberalismo -, que orienta o novo padrão de acumulação do capital na direção da mercantilização da vida. Tudo é e vai se tornando cada vez mais mercadoria, inclusive os seres humanos, que se tornam descartáveis.

A atual crise, que atinge não só o Brasil, mas toda a América Latina e os ditos países desenvolvidos (KATZ, 2010), poderá colocar em questão, de modo forte, a ideia de que a história não pode seguir outro curso, que não o ditado pelo capital. Existe resistência em diversos países e há a possibilidade de revigoramento do pensamento crítico em escala global, o que é fundamental para uma práxis comprometida.

Nesse contexto de crise, enquanto que, para muitos, Paulo Freire já teve o seu momento, para outros, assim como nós, sua proposta educativa, além de atual, é necessária para as classes populares. E, por que não dizer para a humanidade?

Neste artigo, nosso objetivo é o de estabelecer uma relação entre a Pedagogia do Oprimido, de Paulo Freire, formulada há cinquenta anos, e a luta de libertação das mulheres. Para tanto, nossa abordagem será o materialismo histórico dialético e nos servimos, igualmente, além do próprio Freire e de outros estudiosos, de textos de nossa própria autoria, que são resultantes de trabalhos de pesquisa e de extensão. Nesse sentido, a especificidade de nossa contribuição está em refletir sobre o processo de libertação das mulheres, tendo como referente a categoria de opressão de Paulo Freire, assim como, considerar a importância de sua Pedagogia Libertadora para os processos liberadores.

Para cumprir com o nosso objetivo, organizamos o artigo da seguinte forma: num primeiro item, apresentamos nosso entendimento acerca da categoria de opressão de Freire, assim como do papel da pedagogia nos processos educativos; num segundo momento, refletimos sobre a história das mulheres no Brasil, em que se comprova a justeza da categoria Freiriana para a leitura do processo vivido pelas mulheres, assim como sobre a atualidade de sua luta; num terceiro momento, estabelecemos a relação entre o movimento de libertação e as utopias que direcionem a construção de outra sociabilidade humana, em todos os aspectos e dimensões. Ao fim, tecemos algumas considerações.

\section{A categoria da opressão e a pedagogia da libertação em Freire}


Como se analisou em outra oportunidade, a opressão é uma categoria complexa porque implica diretamente na dinâmica sociocultural das sociedades e envolve um conjunto de aspectos que a conformam: políticos, econômicos e culturais.

A afirmação quase sempre feita, quando se discute a categoria de opressão para a análise da realidade, é a de que oprimidos somos todos, em alguma medida. A afirmação é correta, quando se toma a totalidade das dimensões da opressão, mas esta categoria, quando distingue o opressor e o oprimido, também remete as relações de produção/trabalho e a alienação disso decorrente, por parte das classes populares, que são os que não conseguem reproduzir a vida material com o mínimo de dignidade. $\mathrm{O}$ que não significa que os que, como resultado do seu emprego, conseguem reproduzir sua vida material, não sejam oprimidos e igualmente alienados. Para estes, no entanto, a libertação não se configura como um caso de garantir a vida, ou de morte em vida, como para os sem comida, sem teto, sem condições de arcar com condições de saúde... (PALUDO, 2010a, p. 48-49).

Essa capacidade de estabelecer a relação entre as diferentes classes e os segmentos em seu interior, e a radicalidade da compreensão das relações entre as singularidades, especificidades e a totalidade, se expressa em Freire (1995) quando este anuncia que sua luta contra o capitalismo se funda na perversidade intrínseca e na natureza anti solidária do sistema. Quer dizer, a ordem social injusta é a fonte da opressão. Os oprimidos - poderíamos dizer os mais oprimidos - são, para o autor, os condenados da terra, os esfarrapados do mundo, as classes populares, os sem dinheiro, sem poder, sem trabalho, sem terra, os subempregados. Nas palavras de Freire

O importante, porém, é reconhecer que os quilombos tanto quanto os camponeses das Ligas e os sem-terra de hoje todos em seu tempo, anteontem, ontem e agora sonharam e sonham o mesmo sonho, acreditaram e acreditam na imperiosa necessidade da luta na feitura da história como "façanha da liberdade". (...) apostaram na intervenção no mundo para retificá-lo e não apenas para mantê-lo mais ou menos como está.

Se os sem-terra tivessem acreditado na "morte da história", da utopia, do sonho; no desaparecimento das classes sociais, na ineficácia do testemunho do amor à liberdade; se tivessem acreditado que a crítica ao fatalismo neoliberal é a expressão de um neobobismo que nada constrói; se tivessem acreditado na despolitização da política, embutida nos discursos que falam que o que vale hoje é "pouca conversa, menos política e só resultados", se, acreditando nos discursos oficiais, tivessem desistido das ocupações e voltado não para as suas casas, mas para a negação de si mesmos, mais uma vez a reforma agrária seria arquivada (FREIRE, 2003, p. 60-61).

É a partir desse entendimento, que não nega as estruturas instituídas, e nem o sistema perverso de exploração e expropriação, que se caracteriza a sociedade capitalista, na qual Freire estabelece relações entre a política, a economia e a cultura, ao mesmo tempo em que esclarece o papel da cultura e a consciência que desperta, ou melhor, reifica nos oprimidos.

A dialética opressor/oprimido, de acordo com Freire (2003), 
ocorre porque a estrutura do pensar dos oprimidos se encontra condicionada pela situação concreta/existência, na qual se formam. O oprimido hospeda o opressor, quer dizer, é hospedeiro do opressor. Vive uma dualidade, na qual "ser é parecer e parecer é parecer com o opressor". O desconhecimento de si mesmo como oprimido se encontra prejudicado pela situação de imersão na realidade opressora. Na medida desta descoberta, o oprimido, superando o medo da liberdade, torna-se homem em processo de libertação, o que implica em opção, autonomia, responsabilidade e uma entrega à práxis libertadora (teoria e prática). A práxis, para o autor, é reflexão e ação dos homens sobre o mundo para transformar. Sem ela é impossível avançar na superação da relação opressor-oprimido. É necessário engajamento (PALUDO, 2010a, p. 49).

O professor Antonio Andreolla (1999) interpreta as dimensões da opressão das classes populares presentes na obra de Freire.

\begin{abstract}
$\mathrm{Na}$ obra de Freire existe uma opressão antropológico-cultural, que mata a cultura e o conhecimento do outro, o condenando a "cultura do silêncio"; psicológica, que enfraquece o eu permitindo, como consequência, a sua coisificação; ontológica, que promove o ser menos e a desumanização; econômica, que permite que ricos estejam cada vez mais ricos e os pobres cada vez mais pobres; política, por meio da ação do poder central, isto é, ou são leis que beneficiam e privilegiam alguns, ou são medidas provisórias. O povo, na prática, não é soberano, não participa do poder e as necessidades da grande maioria não são atendidas. Há, também, uma opressão pedagógica, que se estabelece na forma de leis que, na prática, retrocedem às conquistas e desejos da comunidade educativa, na concepção educativa implementada e no relacionamento entre professores e estudantes (PALUDO, 2010a, p. 48).
\end{abstract}

Decorrente do conjunto destas opressões, para Freire (2003), a consciência dos oprimidos é uma consciência imersa, fatalista e de autodesvalia.

Ainda, como já se analisou Conceição Paludo (2010, p. 253), no verbete sobre a manipulação, para o Dicionário Paulo Freire, na dinâmica social, para Freire (2003, p. 137),

[...] a manipulação expressa às tentativas "das elites dominadoras" conformar as massas populares aos seus objetivos. Quanto maior a imaturidade política das massas, mais fácil se torna a manipulação porque os oprimidos passam a acreditar nos mitos, tal como o "de que a ordem opressora é uma ordem de liberdade". Para o autor, "antes da emersão das massas não há propriamente manipulação, mas o esmagamento total dos dominados" (p. 145). A manipulação se faz necessária quando as massas, organizadas, estão "emersas e emergindo". Freire cita como exemplo o populismo, que se instaura como um estilo de ação política, quando há a emersão das massas. Ao emergir, as massas, ou são manipuladas pelas elites ou se organizam verdadeiramente para a sua libertação.

Assim como na relação entre países, "Freire (1980) diz que a sociedade dependente é manipulada pela dirigente. A manipulação é utilizada como uma estratégia para a invasão cultural. Os dominados incorporam os mitos culturais, tornando-se uma sociedade 'sem voz', 'silenciosa"” (PALUDO, 2010b, p. 253). 
$\mathrm{Na}$ relação entre educador e educando, a manipulação acontece toda vez que a diretividade se torna autoritarismo e

\begin{abstract}
há a interferência do educador na "capacidade criadora, formuladora, indagadora do educando, de forma restritiva (FREIRE, 2006, p. 79). Nesse caso, "de posse do conteúdo e dos métodos com que manipula os objetos, o educador manipula também os educandos" (p. 113). Assim, apesar do discurso progressista, o educador concretiza a educação Bancária, domesticadora. Do mesmo modo, a manipulação acontece quando a liderança "revolucionária", no trabalho organizativo, pretende "encher a consciência vazia dos grupos populares com a consciência de classe trabalhadora que, segundo ele ou ela, os trabalhadores não têm" (p. 116). Para Freire (1995, p. 61), as organizações populares e os partidos de esquerda precisam esquecer qualquer "ranço de vanguardismo", em favor de uma "descentralização realmente democrática", o que implica a liderança renunciar à ordodoxia, aos mitos e às verdades absolutas (PALUDO, 2010, p. 253-54).
\end{abstract}

Quanto à pedagogia da libertação, no prefácio da obra Pedagogia do Oprimido (2003), Maria Fiori assim se expressa, demonstrando a atualidade da pedagogia do oprimido para a análise da realidade no tempo presente: "nessas sociedades, governadas pelos interesses de grupos, classes e nações dominantes, a 'educação como prática da liberdade' postula, necessariamente, uma 'pedagogia do oprimido'” (2003, p. 6). Não pedagogia para ele, mas dele. Os caminhos da liberação são os do oprimido que se libera: ele não é coisa que se resgata, é sujeito que se deve autoconfigurar responsavelmente.

\begin{abstract}
A prática da liberdade só encontrará adequada expressão numa pedagogia em que o oprimido tenha condições de, reflexivamente, descobrir-se e conquistar-se como sujeito de sua própria destinação histórica. Uma cultura tecida com a trama da dominação, por mais generosos que sejam os propósitos de seus educadores, é barreira cerrada às possibilidades educacionais dos que se situam nas subculturas dos proletários e marginais. Ao contrário, uma nova pedagogia enraizada na vida dessas subculturas, a partir delas e com elas, será um contínuo retomar reflexivo de seus próprios caminhos de liberação; não será simples reflexo, senão reflexiva criação e recriação, um ir adiante nesses caminhos: "método", "prática de liberdade", que, por ser tal, está intrinsecamente incapacitado para o exercício da dominação. (FIORI, 2003, p. 9)
\end{abstract}

Como é possível constatar, a pedagogia do oprimido coloca os esfarrapados do mundo na história. História marcada por discriminação de classe, raça e gênero. As mulheres estiveram historicamente esfarrapadas. Esfarrapadas porque oprimidas na história, história que privilegiou os homens brancos e ricos. A cultura do silêncio, conhecida pelas mulheres, sempre esteve presente. Para Freire (1984), a cultura do silêncio corresponde a um conjunto de representações e comportamentos ou de "formas de ser, pensar e expressar" que é consequência de uma estrutura de dominação secular na América Latina. Segundo Venício Lima (2018), A primeira referência da cultura do silêncio vinculada à opressão da mulher é quando Freire discute "a situação concreta de opressão e os opressores", ainda no capítulo 1 (cf. [Freire, 2018], pp. 61-67)· Ao Revista Interinstitucional Artes de Educar. Rio de Janeiro, V. 4 N. 2 - pag 243-256 (mai - ago 2018): "Dossiê 50 anos da Pedagogia do Oprimido: movimentos de opressões e emancipações contemporâneas na América Latina e África" DOI:10.12957/riae.2018.38026 
tratar da "adesão e consequente passagem que fazem representantes do polo opressor ao polo dos oprimidos" (idem, p. 65) - aos quais tem cabido um papel fundamental na luta pela libertação -, Freire argumenta que, quando esta passagem ocorre, condicionados pela cultura do silêncio, na maioria das vezes, os "convertidos" trazem consigo preconceitos, deformações, desconfianças e uma profunda descrença na capacidade dos oprimidos de se tornarem sujeitos de sua própria História.

\section{As oprimidas e o feminismo no Brasil}

Ivone Gebara (2016, p. 120) afirma que um dos grandes desafios que nosso tempo nos impõe "é o de resignificar palavras e expressões de uso comum que acreditamos "claras e distintas' para todo mundo". Esta necessidade se impõe porque também "estamos assistindo a uma espécie de 'babel' de significados dados à expressão 'educação popular' que, de certa forma, dificultam a compreensão de seu significado histórico originário e dos novos que estamos lhe atribuindo" (2016, p. 122). Tentar precisar a compreensão da "expressão é de certa forma explicitar melhor a nossa ação educativa nos confusos meandros da história presente. E não só isso, é um convite da filosofia a não tomamos conceitos como absolutos, a refazer seus caminhos e significados" (2016, p. 123) como tarefa renovada do pensamento.

Em um texto intitulado Movimento Feminista no Brasil e América Latina: reflexões sobre educação e mulheres, publicado pela revista contraponto ${ }^{1}$, de autoria de Amanda Motta Castro e Rita Machado, discutimos três conceitos importantes para articular a ideia de que o feminismo foi historicamente a luta das oprimidas da história. Esses três conceitos são fundamentais para os Estudos Feministas: resitência, gênero e patriarcado.

Preocupantemente, algumas pesquisadoras têm extraído o conceito de patriarcado dos estudos de gênero. Entendemos que ambos os conceitos -gênero e patriarcado - são fundamentais quando a base de trabalho são os Estudos Feministas.

Quando abordamos tais conceitos, passa a ser fundamental a retomada da reflexão de Graciela Hierro (2007, p. 14):

(...) se há superado y ala etapa del feminismo, creo yo, em que se daba la lucha de las mujeres em contra de los hombres concretos, padres, hermanos, esposos, mantes, hijos y se combatia la ideologia patriarcal en la figura del hombres con la que se entabla la relación interpesonal. O contra las mujeres que constituían la cara feminina del patriarcado.

\footnotetext{
${ }^{1}$ Publicado em Revista Contrapontos - Eletrônica, Vol. 16 - n. 1 - Itajaí, jan-abr 201629 ISSN: 1984-7114. 
A partir desta perspectiva, compreendemos que nossa luta não é contra pessoas físicas, e que tanto homens como mulheres contribuem para a manutenção da sociedade patriarcal. Desse modo, entendemos o conceito de gênero, tal como desenvolvido no bojo dos Estudos Feministas, ideológico e politicamente produzido nas lutas dos movimentos sociais de mulheres como ferramenta de resistência destas, que, historicamente, estiveram também pela ideologia de classe.

De acordo com Marta Lamas (2002), o conceito de gênero começa a ser utilizado nas ciências sociais como categoria a partir da década de 1970. Desde então, a academia passa a trabalhar com ele, abordando como é construído social e culturalmente o ser homem e mulher. Para a mesma autora, é importante destacar que "hay que tener siempre presente que entre mujeres y hombres hay más semejanzas como espécie que diferenças sexuales" (LAMAS, 2011, p. 37).

Nesta abordagem, gênero é a aprendizagem que acontece nas relações socialmente produzidas entre homens e mulheres e destes entre si. Portanto, homens e mulheres aprendem a ser o que são na cultura em que estão inseridos. Seguindo este referencial, as pessoas adultas nos ensinam, desde a infância, como devemos ser homens ou mulheres para sermos socialmente aceitos (SAFFIOTI, 2004). Ou seja, a velha e boa conceituação de Simone de Beauvoir (2009) configura-se como eixo: aprendemos a ser mulheres e homens. E como estamos inseridos no contexto histórico-patriarcal, aprendemos a ser heterossexuais (homens e mulheres). As mulheres aprendem a ser de alguém e para os outros (LAGARDE, 2011); e o homem aprende que deve dominar a mulher, mesmo que ela possa ser a "rainha do lar", a madresposa, que produz a manutenção da lógica patriarcal, segundo Lagarde (2011), Edla Eggert e Márcia Paixão (2012).

O conceito de resistência está presente e representa um marco na recomposição do campo anticapitalista do feminismo, como parte dos retrocessos dos movimentos populares, em particular na década de 1990; com a queda do Muro de Berlim, em 1989; e com a desestruturação da União das Repúblicas Socialistas Soviéticas (URSS), quando o socialismo experimenta o descrédito e o neoliberalismo se instala com maior força. Nesse período, prevaleceu a hegemonia de uma profunda institucionalização e de uma agenda centrada nos aspectos normativos. Assim, frente à globalização neoliberal, não houve uma visão crítica global que integrasse as dimensões econômica, política e social (CADERNOS DA MARCHA MUNDIAL DAS MULHERES, 2006). 
Para análise, Ferrer (2001, p. 67) fundamenta-se em Marcela Lagarde e Michelle Fine e outras/os teóricas/os feministas, ao trabalhar com as categorias de resistência, enfrentamento e poder. Para ela, o conceito de resistência é mais amplo do que o de enfrentamento:

A resistência ocorre no lugar em que ocorre o poder, ou seja na relação de casamento, na família ou na comunidade. Enquanto o enfretamento é a resposta a um incidente específico de violência, a resistência se exerce através de toda a relação de violência onde quer que se exerça o poder.

Resistir é a própria vida das mulheres que lutam contra o patriarcado e o capital. O fato de mulheres participarem desses movimentos de resistência ao patriarcado faz - e continua fazendo - com que elas possam se ver como protagonistas na cena política e de forma coletiva, o que é fundamental na luta.

O patriarcado é o sistema de dominação vigente, surgido por meio da divisão do trabalho e da divisão sexual do trabalho, da sociedade de classes. Neste sentindo,

(...) entendemos que o capitalismo incorporou o patriarcado como estruturante das relações sociais. Para isso, aprofundou a divisão sexual do trabalho, fortalecendo uma divisão entre uma esfera pública e outra privada, a primeira considerada o lugar onde se dá a produção e a segunda onde se dá a reprodução (CADERNOS: MARCHA MUNDIAL DAS MULHERES, 2006, p. 3).

Nesse sentido, o patriarcado baseia-se na divisão sexual do trabalho, construindo-se a partir da escravidão feminina em processos históricos religiosos de transformação "das deusas" em "o Deus", os quais constituem as três grandes religiões. Ao atravessar os diferentes modos de produção, o patriarcado impregnou-se no inconsciente da humanidade e até hoje constitui nossas identidades e modos de pensar, mesmo que dele não tenhamos consciência. Assim, para muitas pesquisadoras feministas (SAFFIOTI, 2004; HIRATA, 2010; FARIA, 2005), o patriarcado continua a ser condicionante nas relações sociais, e seu uso deve ser retomado pelas teóricas contemporâneas, reconhecendo-o como um fenômeno estruturante da sociedade.

Portanto, o patriarcado seria uma forma de dominação masculina disseminada nas diferentes instituições sociais, as quais atribuem ao homem o poder sob todas as formas, sobre todas as posses, incluindo as mulheres e as crianças. É uma ideologia que, por meio da socialização, naturaliza relações de opressão historicamente construídas.

Como ressalta Heleieth Saffioti (2004, p. 101), “além de o patriarcado fomentar a guerra entre as mulheres, funciona como uma engrenagem quase automática, pois pode ser acionada por qualquer um, inclusive mulheres". E logo em seguida a autora define o patriarcado como "um regime que se ancora em uma maneira de os homens assegurarem-se para si mesmos e para seus dependentes os meios diários para a produção e reprodução da vida" (SAFFIOTI, 2004, p. 105). 
Não temos dúvida de que os escritos de feministas europeias e estadunidenses contribuíram para a reflexão e luta feminista na América Latina inteira. Contudo, as experiências de vida de mulheres da América Latina são distintas e, desse modo, o movimento organizado por mulheres deste lugar geográfico tem suas bandeiras e peculiaridades.

Feminismo é um movimento social, filosófico e político que busca a igualdade entre os sexos e uma vivência humana por meio do empoderamento feminino, além da libertação de padrões opressores baseados em normas de gênero. Nas palavras de Saffioti (2007, p. 22):

Os movimentos feministas só são o que são hoje porque foram o que foram no passado. Hoje nós podemos questionar as bases do pensamento ocidental porque houve um grupo de mulheres que queimou sutiãs em praças públicas. O sutiã simbolizava uma prisão, uma camisa de força, a organização social que enquadra a mulher de uma maneira e o homem de outra. A simbologia é essa: vamos queimar a camisa de força da organização social que aprisiona a mulher.

De acordo com Maggie Humm (1990) e Rebecca Walker (1992), a história do feminismo pode ser dividida em três "ondas". A primeira teria ocorrido no século XIX e início do século XX; a segunda, nas décadas de 1960 e 1970; e a terceira, na década de 1990 até a atualidade.

No Brasil, o movimento feminista criou forma entre o fim do século 20 e início do 21 , quando as mulheres brasileiras começaram a se organizar e conquistar espaço na área da educação e do trabalho. Três grandes momentos marcam o movimento feminista no Brasil. O primeiro foi marcado pelas reivindicações por direitos democráticos como o direito ao voto, ao divórcio, à educação e ao trabalho no fim do século 19. O segundo, no fim da década de 1960 , foi caracterizado pela liberação sexual (impulsionada pelo aumento dos contraceptivos). O terceiro momento começou a ser construído no fim da década de 1970, com a luta de caráter sindical e contra a ditadura militar.

Em 1907, surge em São Paulo a greve das costureiras, ponto inicial para o movimento por uma jornada de trabalho de 8 horas. Em 1917, o serviço público passa a admitir mulheres no quadro de funcionários. Dois anos depois, a Conferência do Conselho Feminino da Organização Internacional do Trabalho aprova a resolução de salário igual para trabalho igual.

Hoje a luta feminista ainda continua. Martha Nussbaum (2002) diz que as mulheres são pessoas de segunda categoria no mundo, esfarrapadas ${ }^{v}$. Esta afirmação se sustenta porque as mulheres são mais mal alimentadas; têm um nível menor de saúde; são mais vulneráveis ao abuso sexual, à violência física; são menos alfabetizadas do que os homens; ganham menos que eles e sofrem relativamente mais assédio em espaços de trabalho (NUSSBAUM, 2002).

Assim, o movimento feminista tem como bandeiras principais, hoje, no Brasil, o combate à violência contra a mulher e à discriminação no trabalho, e a legalização do aborto. 


\section{Desde Freire: a construção de utopias}

Nascemos, em condição social, cultural, étnica, de gênero, ou derivada de qualquer escolha ou qualquer vocação, e a única vocação que nos cabe, como seres inacabados, é a de ser mais; convocadas a criarmos e a recriarmos, imperfeita, incompleta e infinitamente, os nossos próprios conhecimentos e os saberes de nossas partilhas ao longo de nossas vidas. Somos chamadas nesse momento histórico a construirmos os nossos mundos de saber e de viver - de com - saber e de co-viver. Melhor ainda, com sororidade e utopias, para neles compartirmos a interação e o diálogo, múltiplas e diferenciadas unidades das escolhas culturais do exercício de nossa libertação. O feminismo faz isso. Importante destacar que dar-se conta da contradição em que estamos inseridas e lutar contra ela é fundamental na construção de utopias e indica algo concreto de mudança. A utopia é algo viável e concreto, por isso deve haver a possibilidade de experiência-lá. O projeto de sociedade precisa ser pensado e articulado entre a classe, entre mulheres e homens.

O feminismo nos tira de lugares onde a dominação masculina, com seu poder patriarcal nos violenta. Como já definimos acima, o feminismo é transformador porque busca nosso empoderamento e a igualdade por poder. Não temos dúvida de que mulheres com poder humanizam a vida, tornando-a fecunda e criativa a todos que nela possam estar. Essa é uma primeira utopia quando falamos de oprimidas a feminista: dividir o poder! Poder esse que historicamente esteve e está nas mãos dos homens, não permitindo nossa vocação de libertação. A pergunta geradora é: por que mulheres não podem dividir o poder, o que implicaria isso?

Implicaria e sermos convocadas a vivermos entre situações de procura interativa e amorosa da vida concreta, através da busca pessoal e solidária de construção de si-mesma e do outro. Algo que estamos e estaremos realizando como seres da pergunta sempre renovada e da pesquisa sempre inacabada. É uma múltipla pergunta, ao mesmo tempo emotiva, racional, ética, estética, intelectual, ativa, existencial, interativa e, no limite, até instrumental, e dirigida a respostas sempre provisórias e, se possível, sempre provocadora de outras perguntas novas e mais complexas.

Em nosso fazer junto com as mulheres, a reflexão da experiência junto ao Movimento das Mulheres Camponesas no Estado do Rio Grande do Sul e das mulheres da Floresta do Amazonas tem demonstrado que há diversas dimensões na nossa luta feminista e, por isso mesmo, nossa luta é emancipadora. Estas dimensões estão relacionadas entre si e, quando assumidas, caracterizam a mulher em processo de libertação.

Revista Interinstitucional Artes de Educar. Rio de Janeiro, V. 4 N. 2 - pag 243-256 (mai - ago 2018): "Dossiê 50 anos da Pedagogia do Oprimido: movimentos de opressões e emancipações contemporâneas na América Latina e África" DOI:10.12957/riae.2018.38026 
A dimensão da luta pessoal é travada na subjetividade. Somos educadas para sermos subservientes e submissas aos homens, para ocupar o espaço doméstico e para servir. Para caminharmos rumo à emancipação, não adianta só compreendermos com a razão (inteligência) que somos discriminadas e exploradas, é preciso querer (vontade) e desejar (emoção) se libertar. É preciso, então, que reeduquemos a subjetividade. A razão, a vontade e a emoção têm que estar integradas, compor um todo coerente, num movimento harmonioso, capaz de conduzir para um novo jeito de ser e de agir.

A dimensão da luta é travada no cotidiano. O movimento da nova subjetividade é acompanhado da ação que a concretiza. Esta ação acontece também no nosso cotidiano, nos mais diversos espaços: família, trabalho, comunidade, círculo de amizades, festas. Enfim, em todos os espaços nos quais vivemos e convivemos. A vigilância demanda constância, porque nesse movimento de fazer diferente, de respeitar e fazer-se respeitar, é que a subjetividade vai se reeducando, vamos ganhando confiança, tendo nossas opiniões, pensando, decidindo e optando, conquistando nosso espaço, sendo sujeitas nas relações e percebendo a beleza do processo de nos realizarmos como gente, como seres humanos.

A dimensão da luta é coletiva. Quanto mais vamos avançando, mais nos damos conta de que a organização da luta para a mudança nas relações de gênero é importante. Quando isso acontece, acabamos percebendo que participar de um Movimento de Mulheres é mais do que poder ter uma folga dos afazeres domésticos ou qualquer outra coisa parecida. Compreende-se que organizar a luta coletivamente representa a possibilidade de incidir para além da nossa vida, na vida de outras mulheres e da sociedade como um todo. Acaba-se querendo para todas as mulheres o gosto de poder ser emancipada, autônoma, realizando-se em outras dimensões que vão além de ser a "rainha do lar", sendo valorizada no trabalho, respeitada como pessoa que tem o direito de escolher e lutar pelo que quer da sua vida. Acaba-se entendendo que neste processo, nos libertando, libertamos os homens que, apesar das vantagens de "serem servidos" pelas mulheres, acabam percebendo que quando buscam ser mais, também são mais completos, porque ninguém consegue ser mais gente, mais pessoa e mais feliz quando, de alguma forma, explora, domina ou oprime o outro.

A dimensão da luta é para além da mudança nas relações de gênero, para que as relações de gênero possam ser mudadas. Este, talvez, seja o momento mais significativo da caminhada de libertação das mulheres. Neste momento, há a compreensão de que as mulheres, além da discriminação de gênero (de raça ou etnia), sofrem a exploração de classe, e a dominação política, juntamente com todos os empobrecidos, independentemente de serem homens ou mulheres. 
Quando as mulheres, individualmente e coletivamente, compreendem que as transformações nas relações de gênero, para acontecerem em nossa sociedade, dependem de outras transformações, elas se transformam de lutadoras das relações de gênero em construtoras e lutadoras de um novo Projeto de Sociedade. Neste momento, elas se inserem num processo de libertação também enquanto classe, lutando duplamente. Isto é, lutando para transformar as relações de gênero e de classe, sendo absolutamente contra qualquer outra espécie de discriminação, como a de raça e a religiosa.

Atuar de forma articulada e coerente, nestas quatro frentes, demonstra uma compreensão profunda de que um novo Projeto de Sociedade requer homens e mulheres libertos de qualquer tipo de exploração, dominação, discriminação e de violência. Participar desta luta é o que nos faz sermos mulheres em processo de libertação porque descentradas, abertas e construtoras das possibilidades de instituição de um projeto de futuro para o Brasil e para a humanidade.

\section{Referências}

ANDREOLA, Antonio Balduino. Interdisciplinaridade na obra de Freire: uma pedagogia da simbiogênese e da solidariedade. In: STRECK et all (Orgs). Paulo Freire: ética, utopia e educação. RJ: Vozes, 1999.

BEAUVOIR, Simone de. O segundo sexo. Tradução de Sérgio Milliet Rio de Janeiro : Nova Fronteira, 2002.

CASTRO, Amanda Motta. ; MACHADO, Rita de Cássia. Movimento Feminista no Brasil e América Latina: reflexões sobre educação e mulheres. Contrapontos (online), v. 16, p. 22, 2016. EGGERT, Edla. A graça do mundo do lado de baixo do equador. In. PEREIRA, Nancy; el alt. A graça do mundo transforma Deus. Porto Alegre: Metodista, 2006.

FARIA, Nalu. Feminismo em movimento: temas e processos organizativos da Marcha Mundial das Mulheres no Fórum Social Mundial. Estudos Feministas, Florianópolis, UFSC. n. 11, p. 623632, fev. 2003. Disponível em: . Acesso em: 1 jun. 2015.

FERRER, D.V. Buenos Aires: Espacio Editorial, 2011.

FIORI, Ernani Maria. Aprender a dizer a sua palavra. In FREIRE, Paulo. Pedagogia do oprimido. 37. ed. Rio de Janeiro: Paz e Terra, 2003.

FREIRE, Paulo. À sombra desta mangueira. São Paulo: Olho d’Água, 1995.

Ação cultural para a Liberdade e outros escritos. 7. ed. Rio de Janeiro: Paz e

Terra, 1984.

Revista Interinstitucional Artes de Educar. Rio de Janeiro, V. 4 N. 2 - pag 243-256 (mai - ago 2018): "Dossiê 50 anos da Pedagogia do Oprimido: movimentos de opressões e emancipações contemporâneas na América Latina e África" DOI:10.12957/riae.2018.38026 
. Conscientização: teoria e prática da libertação. São Paulo: Moraes, 1980.

. Pedagogia da esperança: um reencontro com a Pedagogia do oprimido. 13. ed.

Rio de Janeiro: Paz e Terra, 2006.

. Pedagogia do oprimido. 37. ed. Rio de Janeiro: Paz e Terra, 2003.

HIERRO, Graciella. Ética de la Libertad. Cidade do México: Torres Asociados, 2007.

HIRATA, Helena. Mundialização, divisão sexual do trabalho e movimentos feministas transnacionais. 2010. XI Conferencia Regional Sobre la Mujer de America Latina y El Caribe. Disponível em:

<http://www.cepal.org/mujer/noticias/paginas/2/38882/ponenciacompleta_helenahirata.pdf>. Acesso em: 10 jul. 2014.

.Empleo, responsabilidades familiares y obstáculos socio-culturales. In: América Latina en Movimiento: Feminismo Popular para Cambiar el Mundo. Quito: Alai, v. 489, n. 10, 2013. Mensal.

HUMM, Maggie. The dictionary of feminist theory. Columbus: Ohio State University Press, 1990.

KATZ, Claudio. Neoliberalismo, neodesenvolvimentismo, socialismo. SP: Expressão Popular, 2010 .

LAGARDE, Marcela. Cautiverios de las mujeres: madresposas, monjas, putas, presas y locas. 4. ed. Ciudad del México, 2011.

LAMAS Marta. Cuerpo: diferencia sexual y género. Ciudade del Mexico: Taurus, 2002. UNAM, 2011.

LIMA. Venício. Para além da alfabetização: cultura do silêncio e os 50 anos da pedagogia do oprimido, Carta Maior, 2018. Disponível em < https://www.cartamaior.com.br/?\%2FEditoria\%2FPolitica\%2FPara-alem-da-alfabetizacaocultura-do-silencio-e-os-50-anos-da-pedagogia-dooprimido\%2F4\%2F40403\#.WwsfPtgZG6c.facebook>. Acesso em 28.05.2018 MARCHA MUNDIAL DAS MULHERES (São Paulo). Caderno $9^{\circ}$ Encontro Internacional da Marcha Mundial das Mulheres. 2006. Disponível em: <http://www.sof.org.br/artigos/caderno-9encontro-internacional-da-marcha-mundial- das-mulheres>/. Acesso em: 05 jun. 2015.

NUSSBAUM M. Las Mujeres y el desarrollo humano. Barcelona: Herder, 2002.

PAIXÃO, M.; EGGERT, E. A retomada do conceito de opressão por meio dos cativeiros das mulheres de Marcela Lagarde: questões para debate. Labrys (Edição em Português. On-line), 2012. 
PALUDO, Conceição. Manipulação. In STRECK, Danilo; REDIN, E.; SITKOSKI, J. J. (Org.).

Dicionário Paulo Freire. 2 ed. Belo Horizonte: Autêntica, 2010a.

PALUDO, Conceição. Movimentos sociais e Educação Popular: atualidade do legado de Paulo

Freire. In: STRECK Danilo; GHIGGI:SILVEIRA: PITANO, Sandro (Org.). Leituras de Paulo

Freire: contribuições para o debate pedagógico contemporâneo. Brasília: Oikos, 2010b.

SAFFIOTI, Heleieth. Gênero e patriarcado. In.: VENTURI, Gustavo; RECAMÁN, Marisol;

OLIVEIRA, Suely de. A mulher brasileira nos espaços públicos e privados. São Paulo:

Fundação Perseu Abramo, 2004.

WALKER, Rebecca. Becoming the Third Wave. 1992.

\footnotetext{
i Professora Adjunta na Universidade do Estado do Amazonas - UEA. Pós-Doutora pelo Programa de Pós Graduação em Educação da Universidade do Vale do Rio dos Sinos - Bolsista PNPD/CAPES. Doutora em Educação pelo Programa de Pós Graduação em Educação da Universidade Federal do Rio Grande do Sul - UFRGS na linha de pesquisa Trabalho, Movimentos Sociais e Educação. Onde foi professora substituta entre 2010-2012. Mestre em Educação pela Universidade Federal do Rio Grande do Sul. Especialista em Metodologia do Ensino de Filosofia pela UNISINOS. É licenciada e Bacharel em Filosofia pela Universidade do Vale do Rio dos SinosUNISINOS, Bacharel em Antropologia Social Latino Americana pela UNISINOS. Seus interesses de pesquisa atualmente compreende as problemáticas de Mulheres como: Trabalho, Movimentos Sociais Populares, Feminismos e Economia Feminista.

ii Possui graduação em Pedagogia, especialização em Educação Psicomotora e em Orientação Educacional, mestrado em Educação (1988) e doutorado em Educação (2000), ambos pela Universidade Federal do Rio Grande do Sul. Atualmente é docente no curso de Licenciatura em Educação do Campo e pesquisadora na UFRGS, na Faculdade de Educação - Departamento de Estudos Básicos - e na Linha de Pesquisa Trabalho, Movimentos Sociais e Educação (TRAMSE). Atua no mestrado e doutorado. Tem trabalhado, ao longo dos anos, com processos formais em todos os níveis de ensino - e não formais de educação. Temas centrais trabalhados: Fundamentos da Educação; Educação Popular e Educação do Campo; Educação e Movimentos Sociais; Planejamento, Avaliação e Metodologia de Processos Formativos e Organizativos; Metodologia da Pesquisa em Educação.

iii Professora do Programa de Pós Graduação em Educação da Universidade Federal do Rio Grande do Sul/FURG e docente do Departamento de Educação da mesma instituição. Doutora pelo programa de Pós-Graduação em Educação da Universidade do Vale do Rio dos Sinos/UNISINOS; foi bolsista CAPES durante (2009-2015). É mestra em Educação (2011); Licenciada em Pedagogia (2000) e graduanda em Filosofia (2018). Realizou Estágio de doutoramento na Universidad Autonoma Metropolitana del México - UAM, no departamento de Antropologia. Com o olhar na América Latina tem-se ocupado com os seguintes temas de pesquisa: Feminismo, Educação Popular e processos de exclusão social.

iv Utilizaremos o nome e sobrenome do/a autor/ar na primeira citação. Nas citações seguintes, os/as autores/as passam então a ser mencionados apenas com o último sobrenome. Seguimos essa orientação como uma forma inclusiva de perceber a produção científica. Paulo Freire faz referência à importância do lugar da linguagem inclusiva após ser criticado por sua linguagem machista por feministas norte-americanas que leram sua principal obra - Pedagogia do Oprimido (1964). Freire admite seu machismo e retoma esta questão na Pedagogia da Esperança, publicada em 1992, passando, então, a utilizar uma linguagem.

${ }^{\vee}$ De acordo com o IPEA,2 quase 17 mil mulheres morreram vítimas de agressões entre 2009 e 2011, por causa de conflitos de gênero, ou seja, apenas por ser do sexo feminino. Este número representa uma média de 5.664 mortes de mulheres por causas violentas a cada ano, 472 a cada mês, 15,52 a cada dia ou, ainda, um óbito a cada hora e meia. O feminicídio é a morte de mulher em decorrência de conflitos de gênero, ou seja, pelo fato de ser mulher. A região Nordeste lidera o ranking com a maior taxa de feminicídios do Brasil entre 2009 e 2011, com 6,9 mortes violentas a cada 100 mil mulheres. O segundo lugar pertence ao Centro-Oeste, onde houve 6,86 casos para cada ocorrência 100 mil mulheres. Depois, vem a região Norte, com 6,42. O Sudeste e o Sul têm as melhores taxas: 5,14 e 5,08, respectivamente. (Castro; Machado, 2016, p.29)
}

Revista Interinstitucional Artes de Educar. Rio de Janeiro, V. 4 N. 2 - pag 243-256 (mai - ago 2018): "Dossiê 50 anos da Pedagogia do Oprimido: movimentos de opressões e emancipações contemporâneas na América Latina e África" DOI:10.12957/riae.2018.38026 